\title{
Intraindividual variability of the bioavailability of low dose methotrexate after oral administration in rheumatoid arthritis
}

\author{
C Lebbe, Ch Beyeler, N J Gerber, J Reichen
}

\begin{abstract}
Objectives-To analyse whether the intraindividual variability of the bioavailability of oral methotrexate in rheumatoid arthritis (RA) is as high as the interindividual variability and whether the bioavailability testing can be simplified.

Methods-Fifteen mg methotrexate was given orally after an overnight fast to 10 patients with RA on two occasions, one week $(n=4)$ or two years $(n=6)$ apart, respectively. Plasma samples were taken at specific time intervals and analysed by fluorescence polarisation immunoassay. The areas under the plasma concentration versus time curves from 0 to $\infty$ (AUC) were calculated after fitting to a twocompartment extravascular model with lag time.

Results-The interindividual variability of the AUCs showed a more than five fold range from 77 to $471 \mathrm{~min} \times \mu \mathrm{mol} / 1$. In contrast, the intraindividual differences of AUCs between the two visits ranged from 3 to $100 \mathrm{~min} \times \mu \mathrm{mol} / \mathrm{l}$, reflecting a $3-30 \%$ change in nine of 10 patients. Close correlations were found between the AUCs and the plasma concentrations with a most pronounced correlation eight hours after methotrexate intake $(r=0.975$; p $<0.001$ ).

Conclusions-The high interindividual variability of the AUCs was confirmed. Conversely, only a modest intraindividual variability was disclosed. Plasma sample analysis at a single time point four to eight hours after methotrexate application could simplify estimation of the bioavailability.
\end{abstract}

(Ann Rheum Dis 1994; 53: 475-477)

University of Berne,

Switzerland

Department of Clinical

Pharmacology

C Lebbe

J Reichen

Department of

Rheumatology

Ch Beyeler

N J Gerber

Correspondence to: Dr Christine Beyeler, Department of

Department of Rheumatology, Inselspital,

Rheumatology, Insel Switzerland.

Accepted for publication 2.1 March 1994 pharmacokinetics between and intravenous administration, our could show bioavailabilities ranging from 28 to $94 \%{ }^{1}$ This was confirmed by other data comparing oral and intramuscular administration, revealing bioavailabilities ranging from 45 to $88 \% .^{2}$ Bioavailability was not affected by food. ${ }^{13}$

In view of the interindividual differences in oral pharmacokinetics, the parenteral application would be preferable to assure complete absorption and prolonged exposure to the drug. This would produce a better clinical efficacy, ${ }^{2-7}$ but lead to more inconveniences and higher costs.

On theoretical grounds, the oral bioavailability could be determined in a given patient before initiation of the methotrexate treatment and an adequate oral dose derived from the pharmacokinetic data. In case the intraindividual variability of the oral bioavailability is low, oral administration would still be justified. The methotrexate dose could be adjusted according to the concomitant drug treatment, renal function and disease activity during the regular follow ups. However, insufficient data are available. We therefore studied 10 fasted patients with RA on two occasions, comparing pharmacokinetics after intake of $15 \mathrm{mg}$ methotrexate in the hope of defining a simplified test of bioavailability.

Patients and methods

PATIENT POPULATION

To study the intraindividual variability of the bioavailability of low dose oral methotrexate, 10 patients (five women, five men) with rheumatoid arthritis (ARA criteria) ${ }^{8}$ were assessed on two occasions (table 1). Body weight did not change by more than $2 \mathrm{~kg}$ between the visits, with the exception of patient number five who gained $5 \mathrm{~kg}$.

All patients were under treatment with low dose intramuscular methotrexate for one week to 35 months on the first visit and nine to 58 months on the second visit. All patients were taking non steroidal anti-inflammatory drugs. In addition, drug treatment included prednisone, ranitidine, verapamil, nifedipine, metformin, glipizide, opipramol, clomipramine, triazolam, midazolam, ferrous sulphate, folic acid and other vitamins in some of the patients.

Only patients with normal renal and hepatic function were included as defined by normal values of plasma creatinine, ALT, AST, galactose elimination capacity ${ }^{9}$ and aminopyrine breath test. ${ }^{10}$

The study was approved by the Human Ethics Committee of the Faculty of Medicine, 
Table 1 Absorption and elimination half lives and area under the plasma concentration versus time curves from time 0 to $\infty$ (AUC) after oral intake of $15 \mathrm{mg}$ methotrexate on two different occasions, in 10 fasted patients with rheumatoid arthritis. To compare half lives and AUCs the Wilcoxon signed rank test was used

\begin{tabular}{|c|c|c|c|c|c|c|c|c|c|c|c|}
\hline $\begin{array}{l}\text { Patient } \\
\text { number }\end{array}$ & $\begin{array}{l}\text { Weight } \\
(\mathrm{kg})\end{array}$ & $\begin{array}{l}\text { Age } \\
\text { (years) }\end{array}$ & $\begin{array}{l}\text { Absorption } \\
\text { (minutes) } \\
\text { visit 1 }\end{array}$ & $\begin{array}{l}\text { half life } \\
\text { visit } 2\end{array}$ & $\begin{array}{l}\text { Elimin } \\
\text { (hours } \\
\text { visit 1 }\end{array}$ & $\begin{array}{l}n \text { half life } \\
\text { visit } 2\end{array}$ & $\begin{array}{l}\text { AUC } \\
\text { (min } \times \\
\text { visit } 1\end{array}$ & $\begin{array}{l}\text { umoll) } \\
\text { visit } 2\end{array}$ & $\begin{array}{l}\text { Change } \\
\text { from visit } \\
\text { (absolute) }\end{array}$ & $2(\%)$ & $\begin{array}{l}\text { Interval } \\
\text { between } \\
\text { the visits }\end{array}$ \\
\hline $\begin{array}{l}1 \\
2 \\
3 \\
4 \\
5 \\
6 \\
7 \\
8 \\
9 \\
10\end{array}$ & $\begin{array}{l}78 \\
59 \\
82 \\
71 \\
75 \\
66 \\
57 \\
62 \\
82 \\
49\end{array}$ & $\begin{array}{l}57 \\
45 \\
55 \\
54 \\
56 \\
66 \\
60 \\
63 \\
66 \\
72\end{array}$ & $\begin{array}{l}41 \cdot 4 \\
30 \cdot 3 \\
17 \cdot 9 \\
20 \cdot 8 \\
27 \cdot 8 \\
41 \cdot 1 \\
16 \cdot 9 \\
18 \cdot 1 \\
40 \cdot 5 \\
14 \cdot 2\end{array}$ & $\begin{array}{l}17 \cdot 7 \\
11 \cdot 6 \\
19 \cdot 8 \\
24 \cdot 6 \\
29 \cdot 5 \\
25 \cdot 1 \\
25 \cdot 6 \\
39 \cdot 7 \\
29 \cdot 6 \\
13 \cdot 4\end{array}$ & $\begin{array}{l}2 \cdot 9 \\
3 \cdot 4 \\
2 \cdot 6 \\
2 \cdot 2 \\
3 \cdot 4 \\
3 \cdot 3 \\
2 \cdot 6 \\
6 \cdot 2 \\
2 \cdot 9 \\
3 \cdot 8\end{array}$ & $\begin{array}{l}2 \cdot 6 \\
4 \cdot 4 \\
4 \cdot 4 \\
2 \cdot 5 \\
2 \cdot 8 \\
3 \cdot 0 \\
3 \cdot 1 \\
6 \cdot 2 \\
2 \cdot 0 \\
6 \cdot 3\end{array}$ & $\begin{array}{l}77 \\
128 \\
139 \\
155 \\
160 \\
204 \\
209 \\
219 \\
236 \\
400\end{array}$ & $\begin{array}{l}177 \\
131 \\
114 \\
145 \\
208 \\
248 \\
226 \\
230 \\
200 \\
471\end{array}$ & $\begin{array}{l}+100 \\
+3 \\
-25 \\
-10 \\
+48 \\
+44 \\
+17 \\
+11 \\
-36 \\
+71\end{array}$ & $\begin{array}{l}+130 \\
+3 \\
-18 \\
-6 \\
+30 \\
+22 \\
+8 \\
+5 \\
-15 \\
+18\end{array}$ & $\begin{array}{l}2 \text { years } \\
2 \text { years } \\
1 \text { week } \\
1 \text { week } \\
2 \text { years } \\
2 \text { years } \\
2 \text { years } \\
2 \text { years } \\
1 \text { week } \\
1 \text { week }\end{array}$ \\
\hline $\begin{array}{l}\text { Mean } \\
\text { (SD) }\end{array}$ & $\begin{array}{l}68 \\
(11)\end{array}$ & $\begin{array}{l}59 \\
(8)\end{array}$ & $\begin{array}{l}26 \cdot 9 \\
(10 \cdot 9) \\
\end{array}$ & $\begin{array}{l}23 \cdot 7 \\
(8 \cdot 4)\end{array}$ & $\begin{array}{l}3 \cdot 3 \\
(1 \cdot 1)\end{array}$ & $\begin{array}{l}3 \cdot 7 \\
(1 \cdot 5)\end{array}$ & $\begin{array}{l}193 \\
(87)\end{array}$ & $\begin{array}{l}215 \\
(100)\end{array}$ & $\begin{array}{l}+22 \cdot 3 \\
(43 \cdot 1)\end{array}$ & $\begin{array}{l}+17 \cdot 7 \\
(42 \cdot 4)\end{array}$ & \\
\hline
\end{tabular}

University of Berne. Written informed consent was obtained from all the patients.

\section{EXPERIMENTAL DESIGN}

After an overnight fast, $15 \mathrm{mg}$ methotrexate (Methotrexate Lederle $6 \times 2.5 \mathrm{mg}$ tablets) was given orally to each patient one week after the regular injection, on two different occasions one week or two years apart, to analyse the effect of a short as well as an extended interval. To reduce interactions, intake of the concomitant drug treatment and food was only allowed at least two hours after the methotrexate ingestion.

Plasma samples were taken before and five, $30,45,60,90,120$ minutes and four, six and eight hours after methotrexate intake. The samples were centrifuged immediately and the plasma kept at $-20^{\circ} \mathrm{C}$ until analysis. Methotrexate plasma concentrations were determined by fluorescence polarisation immunoassay (TDx; Abbott Diagnostics, North Chicago, IL). ${ }^{11}$ Samples of the same patient were analysed on the same day. The lowest detection limit is $0.01 \mu \mathrm{mol} / 1$ as reported by the manufacturer. The intra- and interday coefficients of variation were both $3 \%$ in the present series.

\section{DATA ANALYSIS}

The plasma concentration versus time curves were fitted to a two-compartment extravascular model with lag time as described previously. ${ }^{1}$ One curve (patient 6 , first visit) could only be fitted to a one-compartment extravascular model and in another curve (patient 10, first visit) the lag time had to be omitted. As an estimate of the bioavailability, the areas under the curves from 0 to $\infty$ (AUC) were calculated using the trapezoidal rule method and the computed elimination rate constant.

We omitted the measurement of methotrexate plasma concentrations after eight hours for practical reasons. In our previous study, plasma concentrations 24 hours after intake were only slightly above the detection limit. ${ }^{1}$ In addition, the calculated AUC 0 to $\infty$ was on average (SD) $23.9(4.2) \%$ smaller, when only plasma concentrations up to eight hours were included compared with up to 24 hours. This inaccuracy was felt negligible in view of the high interindividual variability of approximately $400 \%$.

All results are given as mean (SD). The significance level was set at $\mathrm{p}=0 \cdot 05$.

\section{Results}

Methotrexate kinetics showed considerable interindividual differences (table 1). The mean (SD) lag time was $9.9(10.2)$ minutes (ranging from 0.0 to 27.2 ) and $13.5(8.3)$ minutes (ranging from $5 \cdot 7$ to $25 \cdot 7$ ) after the first and second administration, respectively. Peak concentrations were reached after 83 (26) minutes (ranging from 45 to 120) and 93 (22) minutes (ranging from 60 to 120 ) with values of $0.80(0.30) \mu \mathrm{mol} / \mathrm{l}$ (ranging from 0.37 to $1.36)$ and $0.77(0.22) \mu \mathrm{mol} / \mathrm{l}$, (ranging from 0.49 to $1 \cdot 28$ ) respectively.

No obvious reason for the exceptionally long half life of 6.2 hours in patient eight on both occasions could be identified; in particular, renal function and quantitative liver function were normal and there was no concomitant drug treatment that was likely to explain this half life.

The area under the plasma concentration versus time curves from 0 to $\infty$ (AUC) was used as an estimate of the bioavailability. An enormous interindividual variability with a more than five fold range of the AUCs was revealed, despite an only one and a half fold range of the methotrexate dose per body weight $[0.226(0.04) \mathrm{mg} / \mathrm{kg}]$ or body surface $\left[8.7(1 \cdot 1) \mathrm{mg} / \mathrm{m}^{2}\right]$. In contrast, only a moderate intraindividual change over time of the AUCs was found, being less than $30 \%$ in nine of 10 patients (table 1). The sum of squares of the AUCs was 68881 and 90846 $[\mathrm{min} \times \mu \mathrm{mol} / 1]^{2}$ for the first and second visit respectively. The sum of squares of the halved differences of the AUCs between the two visits was $5430[\mathrm{~min} \times \mu \mathrm{mol} / 1]^{2}$. This reveals a far bigger inter- than intraindividual variability of the AUCs.

Patient 1 with an exceptionally low AUC on the first visit and a vast increase on the second visit, two years later, had been taking ferrous sulphate (Resoferon, Geigy Pharma) on the first occasion.

The mean (SD) change of the AUCs was $-5 \cdot 3(16 \cdot 3) \%$ and $33(48 \cdot 7) \%$ for an interval 
Table 2 Correlations between AUCs 0 to $\infty$ and plasma concentrations at different time points (linear regression analyses)

\begin{tabular}{lll}
\hline $\begin{array}{l}\text { Time point } \\
\text { (hour) }\end{array}$ & $\begin{array}{l}\text { Correlation coefficient } \\
(r)\end{array}$ & Significance level \\
\hline 1 & 0.680 & $\mathrm{p}<0.001$ \\
1.5 & 0.859 & $\mathrm{p}<0.001$ \\
2 & 0.853 & $\mathrm{p}<0.001$ \\
4 & 0.963 & $\mathrm{p}<0.001$ \\
6 & 0.963 & $\mathrm{p}<0.001$ \\
8 & 0.975 & $\mathrm{p}<0.001$ \\
\hline
\end{tabular}

between the two pharmacokinetic studies of one week and two years, respectively $(p=0.05$; Wilcoxon rank sum test) (table 1).

High correlations were found between AUCs 0 to $\infty$ and plasma concentrations at different time points, being highest eight hours after methotrexate intake (table 2).

\section{Discussion}

Several studies have demonstrated a large interindividual variability of the oral kinetics of low dose methotrexate in rheumatoid arthritis. ${ }^{12}$ This is, however, the first study illustrating an only moderate intraindividual variability of the oral methotrexate bioavailability over a short as well as long time period. Oral administration with individual dose adjustment therefore appears justified.

Special attention was given to possible interactions. Although intake of the concomitant drug treatment was allowed only after reaching methotrexate peak levels, patient 1 had a more than two fold longer absorption half life resulting in a two and a half times higher AUC a day with intake of ferrous sulphate compared to the day without. Ferrous sulphate can bind to the carboxyl groups of methotrexate in analogy to folic acid, ${ }^{12}$ leading to a less absorbable iron-drug complex. Several studies showed no major changes of methotrexate elimination in patients on non steroidal anti-inflammatory drugs if renal function was normal. ${ }^{13}{ }^{14}$ In our study only patients with a normal plasma creatinine were included. This selection procedure did not exclude the possibility that some of the patients had a slightly impaired renal clearance and therefore might have had an increased risk of drug interaction:
Our demonstration of strong correlations between AUCs and plasma concentrations between four and eight hours after methotrexate intake suggests a simplified estimation of bioavailability and drug monitoring. Thus plasma sample analysis at a single time point could easily be used in daily practice. Further studies will be needed to establish relationships between dose and plasma concentrations as well as plasma concentrations and clinical effect.

We thank the nurses of the outpatient clinic of the Department of Clinical Pharmacology for their willing and skilful help. This study was supported by the Swiss National Foundation (Grant 32.30168 to J Reichen).

1 Oguey D, Kölliker F, Gerber N J, Reichen J. Effect of food on the bioavailability of low-dose methotrexate in patients with rheumatoid arthritis. Arthritis Rheum 1992; 35: with rhe $611-4$.

2 Auvinet B, Jarrier I, Le Levier F, Pegon Y, Turcant A, Allain P. Biodisponibilité comparée du methotrexate par voie orale et intramusculaire dans la polyarthrite rheumatoïde. Presse Med 1992; 21 : 822

3 Kozloski G D, De Vito J M, Kisicki J C, Johnson J B. The effect of food on the absorption of methotrexate sodium tablets in healthy volunteers. Arthritis Rheum 1992; 35 761-4.

4 Freeman-Narrod M, Gerstley B J, Engstom P F, Bornstein $R$ S. Comparison of serum concentrations of methotrexate after various routes of administration. Cancer 1975; 36: 1619-24.

5 Sauvezie B, Dubost J J, Garandeau A, Rampon S. Methotrexate in rheumatoid polyarthritis. Review of the literature. Rev Rhum Mal Osteoartic 1987; 54: 607-15.

6 Seideman P. Methotrexate - the relationship between dose and clinical affect. Br $\mathcal{F}$ Rheumatol 1993; 32: 751-3.

7 Furst D E, Koehnke L, Burmeister L F, Kohler J, Cargill I. Increasing methotrexate effect with increasing dose in the treatment of resistant rheumatoid arthritis. $f$ Rheumatol 1989; 16: 313-20.

8 Arnett F C, Edworthy S M, Bloch D A, et al. The American Rheumatism Association 1987 revised criteria for the classification of rheumatoid arthritis. Arthritis Rheum 1988; 31: 315-24.

9 Tygstrup N. Determination of hepatic elimination of galactose by single injection. Scand f Clin Lab Invest 1966; 19: 118-25.

10 Bircher J, Küpfer A, Gikalov J, Preisig R. Aminopyrine demethylation measured by breath analysis in cirrhosis. Clin Pharmacol Ther 1976; 20: 484-92.

11 Pesce M A, Bodourian S H. Evaluation of a fluorescence polarisation immunoassay procedure for quantitation of polarisation immunoassay procedure for quanti

12 Campbell N R C, Hasinoff B B. Iron supplements: a common cause of drug interaction. Br $\mathrm{f}$ Clin Pharmacol 1991; 31: 251-5.

13 Stewart C F, Evans W E. Drug-drug interaction with antirheumatic agents: review of selected clinically important interactions. F Rheumatol 1990; 17: 16-23.

14 Ahern M, Booth J, Loxton A, McCarthy P, Meffin P, Keva S. Methotrexate kinetics in rheumatoid arthritis: is there an interaction with nonsteroidal antiinflammatory drugs? f Rheumatol 1988; 15: 1356-60. 